\title{
A PERCEPÇÃO DE QUESTÕES AMBIENTAIS POR CRIANÇAS DA EDUCAÇÃO INFANTIL: ESTUDO DE CASO SOBRE AS MUDANÇAS CLIMÁTICA GLOBAIS NO NÚCLEO DE EDUCAÇÃO INFANTIL IPÊ AMARELO
}

\author{
Diana Vandréia Dal Soto', Damaris Kirsch Pinheiro², Djalma Dias da Silveira² \\ Marcelo Barcellos da Rosa² \\ ${ }^{1}$ Especialista em Educação Ambiental \\ ${ }^{2}$ Professores do Curso de Especialização em Educação Ambiental da UFSM
}

\section{RESUMO}

Este estudo investigou, a partir da prática pedagógica cotidiana, a compreensão das crianças da educação infantil sobre as mudanças climáticas globais. Nesse propósito, a pesquisa assume uma abordagem qualitativa, caracterizando-se como um estudo de caso, utilizando como fonte de dados um grupo de crianças da Pré Escola, no Núcleo de Educação Infantil Ipê Amarelo da Universidade Federal de Santa Maria. Os dados apresentados pelas crianças, antes e depois do trabalho desenvolvido, revelam que houve uma ampliação dos conhecimentos prévios do grupo, considerando uma compreensão significativa da temática abordada. Observaram-se, nas relações diárias das crianças no contexto escolar, atitudes preocupadas com a conservação e preservação do meio ambiente como um todo.

Palavras-chaves: Educação Ambiental, Educação Infantil, Mudanças Climáticas.

\section{ABSTRACT}

This study investigated, initializing from the daily pedagogic practice, the children's of infantile education understanding on the global climatic changes. In this purpose, the research assumes a qualitative approach, characterized as a case study, using as source of information a group of preschool children, in the Nucleus of Infantile Education Ipê Amarelo of Universidade Federal de Santa Maria. The information presented by the children, before and after the developed work, reveals that there was an increase of the previous knowledge of the group, considering an important understanding of the thematic approached. Were observed, in the children's daily relationships in the school, concerned attitudes with the conservation and preservation of the environment by entirely.

Keysword: Environmental education, Infantile Education, Climatic Changes.

\section{INTRODUÇÃO}

O Estudo está voltado às práticas de Educação Ambiental em Nível Formal, tendo-se como campo de investigação, uma escola de educação Infantil localizada no Campus da Universidade Federal de Santa Maria - Núcleo de Educação Infantil Ipê Amarelo.

De acordo com o Painel Intergovernamental de Mudanças Climáticas - IPCC (2007) desde a época pré - industrial vem ocorrendo um aumento das concentrações atmosféricas dos gases de efeito estufa (CO2, CH4, N2O, CFC, HFCS, PFCS. O aumento desses gases está relacionado às 
atividades humanas, como a queima de combustíveis fósseis, o desmatamento, as queimadas e desencadeiam um crescimento substancial das temperaturas médias globais

Diante desse quadro, os meios de comunicação informam diariamente sobre a necessidade dos cuidados com o meio ambiente e vem enfatizando, nos últimos tempos, de forma mais acentuada, a problemática mundial que envolve as mudanças climáticas. Com isso, é evidente que as informações invadem todas as famílias, de diferentes classes sociais. Na escola, as crianças demonstram ter acesso a essas informações.

Frente a essas evidências, cabe a escola (re) significar as informações trazidas pelas crianças, de modo que possibilite a (re) construção de conhecimentos, para o desenvolvimento de uma racionalidade que legitime práticas pautadas em valores de dependência, respeito, cuidado e reciprocidade nas relações entre os elementos que compõem o Meio Ambiente.

O Referencial Curricular Nacional para a Educação Infantil (RCNEI) traz importantes indicações metodológicas para o trabalho na educação infantil, principalmente no que se refere ao mundo da criança, a sociedade e a natureza, propõe, dentre seus objetivos gerais, que a criança deve saber "observar e explorar o ambiente com atitude de curiosidade, percebendo-se cada vez mais como integrante, dependente e agente transformador do meio ambiente e valorizando atitudes que contribuam para a sua conservação" (BRASIL, 1998, vol. 1, p.63).

Ainda recorrendo ao Parâmetro Nacional de Qualidade para a Educação Infantil (2006), no volume 2, observa-se que este defende uma perspectiva educacional que respeite a diversidade cultural e promova o enriquecimento permanente do universo de conhecimentos, permitindo, desde cedo

as crianças usufruírem da Natureza, observarem e usufruírem do vento, brincarem com água e areia. Criando condições para que as crianças desfrutem a vida ao ar livre, aprendam a conhecer o mundo da Natureza em que vivemos, compreendam as repercussões das ações humanas nesse mundo e sejam incentivadas em atitudes de preservação e respeito à biodiversidade, estaremos difundindo uma concepção de educação em que o ser humano é parte da Natureza e não seu dono e senhor absoluto (BRASIL, 2006, p. 18). ${ }^{1}$

Assim, diante da necessidade de juntar esforços de instituições sociais para minimizar os impactos causados ao meio ambiente, compreende-se que a educação infantil desenvolve papel fundamental, pois é a atual geração de crianças e seus filhos que estão sujeitos aos maiores impactos das mudanças climáticas, sobretudo do aquecimento global.

Pelo exposto, justifica-se a necessidade de levar a compreensão das questões ambientais ao público infantil, que como cidadãos estão inseridos no contexto social e, por sua vez, participam das mudanças que correm nesse contexto. Desse modo, necessitam do conhecimento das questões que envolvem a problemática ambiental, para que venham a desenvolver ações efetivas para manter o equilíbrio ambiental.

Nesse contexto, torna-se importante (re) pensar: como as práticas cotidianas, na educação infantil podem fazer sentido e criar campos favoráveis para a educação ambiental. Além disto, com a problemática do aquecimento global, como ocorre a apropriação de conhecimentos necessários à construção de uma compreensão das problemáticas ambientais por crianças em idade pré-escolar.

A partir dessas reflexões desenvolvem-se ações educativas com uma turma de pré-escola, com idades entre cinco e seis anos, onde se aborda o tema aquecimento global, buscando verificar a

1 Parâmetro Nacional de Qualidade para a Educação Infantil citando Tiriba (2005) 
compreensão das crianças sobre as questões ambientais, como as mudanças climáticas globais; estimular e fortalecer uma consciência e posturas críticas sobre a problemática ambiental e incentivar a participação individual e coletiva na preservação do equilíbrio do Meio Ambiente.

\section{METODOLOGIA}

A metodologia adotada nesta investigação assume uma abordagem qualitativa (MINAYO, 2001). Através de um estudo de caso, utiliza-se como fonte de dados um grupo de crianças da Pré Escola, no Núcleo de Educação Infantil Ipê Amarelo da Universidade Federal de Santa Maria, buscando, nesse cenário, o maior número de elementos, para permitir o estudo detalhado do tema, possibilitando revelar as várias dimensões do problema em questão.

Utilizou-se como técnica de coleta de dados e evidências, a Pesquisa-Ação, que segundo Martins (2006) "é uma estratégia de pesquisa que se adéqua aos propósitos do estudo de caso" (p.47). Pois consiste em unir pesquisa e ação em um processo que os atores implicados participam juntamente com o pesquisador.

Também foram realizadas observações, que segundo Martins (2006, p. 23), "são procedimentos empíricos de natureza sensorial", que permitem a coleta de dados de situações e envolvem a percepção sensorial do observador.

Para tanto, a coleta de informações aconteceu através de registros das falas das crianças durante as atividades e interações no contexto escolar, fotografias dessas interações, como também pela análise de desenhos realizados pelas crianças. O diário de campo foi o instrumento utilizado para os registros das impressões e percepções em relação às interações das crianças e suas falas durante o trabalho.

As atividades foram realizadas com a Pré Escola. A turma está composta por 20 crianças, com idade entre 5 e 6 anos. Nesse trabalho as crianças estão identificadas pelas letras iniciais de seus nomes.

As atividades propostas ao grupo foram planejadas com referência em três momentos, buscando num primeiro momento verificar a compreensão inicial do tema, em um segundo momento proporcionar o estudo do tema e, por fim, discutir e incentivar ações, verificando as aprendizagens do grupo.

Com esse propósito foram realizadas as seguintes atividades:

- Rodas de conversa: nessas rodas de conversas as crianças foram questionadas, inicialmente o que você entende sobre aquecimento global? E posteriormente o que você pode fazer para minimizar o aquecimento global?

- Projetados Vídeos: 'WWF- Brasil - Mundo'² (possibilita a compreensão das transformações que o Planeta Terra sofreu e poderá sofrer) e a História 'Aquecimento Global em Livro Animado'3 (explica o que é o aquecimento global).

- Passeio no campus UFSM, com a finalidade de observar o meio ambiente e recolher materiais para a construção dos experimentos;

- Experimentos: 'efeito estufa' (demonstrar o efeito estufa e correlacionar ao aquecimento global) terrário' (demonstrar como a vida se sustenta e relacionar ao efeito estufa), 'testando a

\footnotetext{
${ }^{2}$ Disponível em: http://www.youtube.com/watch?v=ZOOpxz0w--8.,

${ }^{3}$ Disponível em: http://iguinho.ig.com.br/turmadosuperv/livro_aquecimento.html,
} 
decomposição' (observar que os materiais se decompõem em tempos diferentes e podem poluir o meio ambiente);

- Plantio de árvores no pátio da escola

- Construção de brinquedos (reaproveitamento de materiais)

\section{RESULTADOS E DISCUSSÃO}

Ao iniciar o estudo, na primeira atividade - a entrevista, as crianças mostraram-se envolvidas na proposta. Demonstrando entusiasmo pelas descobertas que os estudos lhes proporcionavam. Também, revelaram, nesse momento inicial, possuírem noções a cerca da temática instigada.

Nesse contexto, leva-se em conta que as crianças já trazem conhecimentos prévios, e para tanto, são vistas como "sujeitos que tem suas próprias teorias sobre o mundo e o seu funcionamento" (Barbosa \& Horn, 2008, p. 42). Assim, as novas construções de conhecimentos devem considerar as precedentes, para problematizar e reconstruir os conhecimentos.

No segundo encontro, em que se buscou ressignificar os conhecimentos, com auxílio do vídeo: 'WWF - Brasil - Mundo' e da história 'Aquecimento global em livro animado', as crianças participaram com bastante envolvimento, dando continuidade a esse envolvimento nos momentos subseqüentes, onde falaram e representaram em seus desenhos as novas compreensões sobre o assunto.

Ao apresentarem e explicarem seus desenhos, observou-se que houve a apreensão de novos conhecimentos por parte de todas as crianças. Cada criança expressa de uma forma particular sua compreensão das ações humanas, como o desmatamento, queimadas, o destino inadequado para o lixo, a poluição gerada pelas indústrias e automóveis, e as conseqüências que as mesmas desencadeiam no planeta.

Na Figura 1, vê-se a representação feita por um dos alunos do Sol e da Terra, sendo que a Terra recebe calor do Sol e este fica retido, conforme indicado nas manchas alaranjadas. Esta criança, ao explicar o seu desenho, fala - "o Sol está mandando calor para o planeta e o planeta não devolve, porque estão jogando lixo, botando fogo nas florestas e fazendo fumaça".

Esse entendimento também é destacado no desenho da Figura 2, em que fica expressa a compreensão da criança sobre o desmatamento e a poluição, sendo que a mesma acrescenta em sua fala: "o Sol esquenta a Terra e as árvores estão sendo cortadas e também estão jogando lixo no mar e os peixes estão morrendo, o gelo está derretendo."

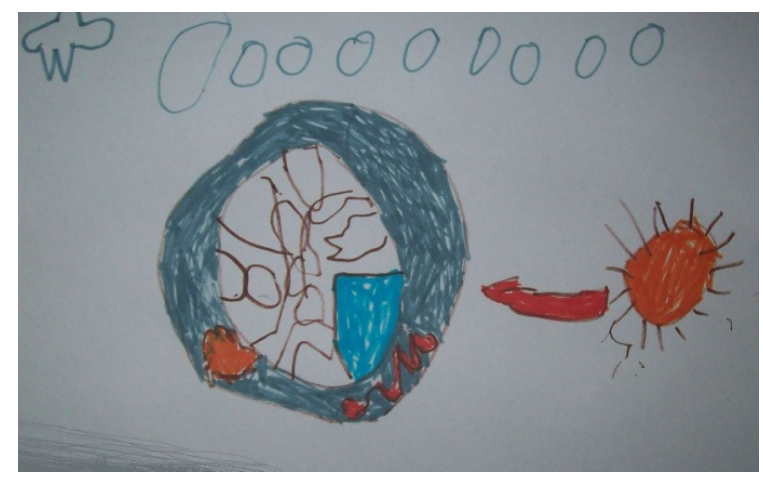

Fig.1: Desenho de F.P, seis anos

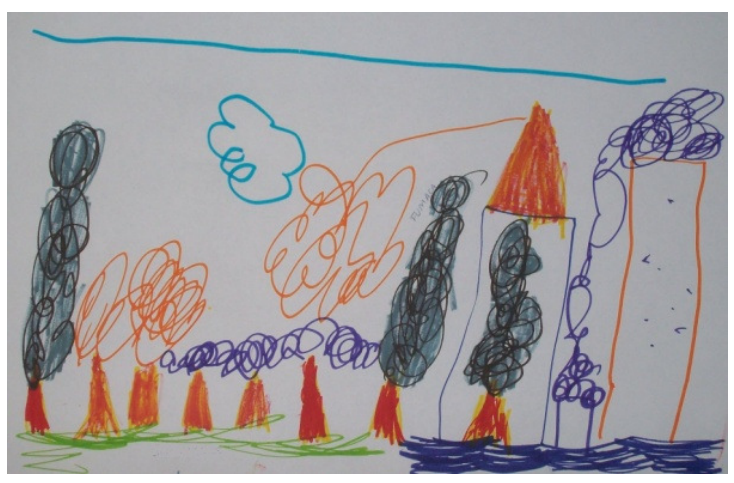

Fig.2: Desenho de E.B, cinco anos 
Na seqüência desse trabalho, com o experimento "efeito estufa", percebe-se ainda mais as aprendizagens do grupo. Ao observarem o experimento logo concluíram que iria esquentar mais a água de dentro da caixa, porque o Sol, representado pela lâmpada, iria passar o calor para água. No desenho (Figura 3) a criança faz a sua interpretação do experimento, ao desenhar o planeta Terra, representando a atmosfera terrestre e o Sol. Compreende que através do processo natural, o Sol aquece a Terra, o que gera o efeito estufa.

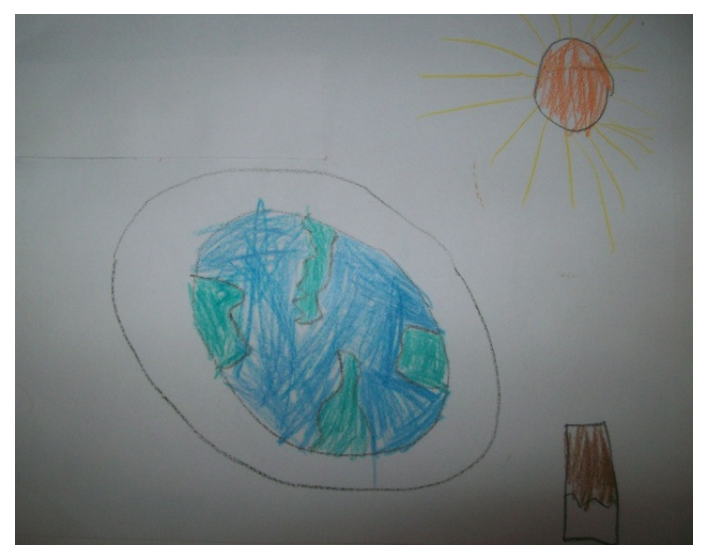

Fig.3: Desenho de A.C., cinco anos

No passeio, ouve a interação de todos do grupo, nas observações ao meio ambiente, percebendo as interferências humanas, como o lixo jogado no chão, o contato com as plantas e animaizinhos. Todas essas interações dão continuidade às aprendizagens anteriores, como no caso do segundo experimento, o terrário, em que as crianças participaram com alegria de todos os passos da construção do experimento e, enquanto realizavam essa construção chegaram à conclusão que se tratava da confeç̧ão de um "planetinha" e que o Sol iria esquentar, conforme o experimento anterior. Posteriormente, se sentiram instigadas a colaborar no estudo, trazendo para a sala informações de pesquisas realizadas em casa e compartilhando suas contribuições.

Desse modo, as aprendizagens tornam-se significativas às crianças. Freire (2004, p. 69) coloca que aprender "é uma aventura criadora", o que não acontece pela repetição de lições, é preciso "construir, reconstruir, constatar para mudar, o que não se faz sem abertura ao risco e a aventura do espírito".

Nesse sentido, as interações, observações e experimentações possibilitadas através das atividades, colaboram para a organização do pensamento reflexivo da criança, pois as dinâmicas, os problemas e conflitos apresentam-se como situações desafiadoras, que instigam ao diálogo, reflexão e, consequentemente, a formação de sujeitos críticos em relação ao ambiente.

A construção do terceiro experimento, 'testando a decomposição', possibilitou, através do concreto, a visualização do que acontece com o lixo que é produzido e descartado pelo homem. A partir disso, observou-se a mobilização das crianças em separar o lixo e mobilizar outras pessoas, como seus familiares. No ambiente escolar, as observações e indagações das crianças sobre aquilo que não estava de acordo com o julgado correto se fez constante.

Assim, comprova-se que as descobertas possibilitaram a inserção das crianças nos processos de observação do meio e das relações entre os seres que compõem esse meio. Com isso, concorda-se com a defesa de Henn \& Bastos (2008) ao colocarem que as aprendizagens dos conceitos, valores, atitudes e procedimentos ocorrem de forma contextualizada, por isso 
tem-se a obrigação de Ihes oferecer uma prática educativa ambiental associada aos conhecimentos mais elaborados, mesmo quando se refere às crianças pequenas, que contribuam para a iniciação da sua formação e de um cidadão crítico capaz de interferir na sua realidade e no contexto onde está inserido (Henn \& Bastos, 2008, p.335).

$\mathrm{Na}$ discussão de ações para minimizar o Aquecimento Global colocam-se como seres atuantes nesse processo e ainda mobilizaram ações coletivas para a sala de aula, como relação aos cuidados com os jogos, brinquedos, uso racional da energia elétrica e da água. Assim coloca a criança F. P "toda a vez, quando não olho mais TV e quando quero ir brincar, desligo a TV. E, também, se eu fizer os meus brinquedos e inventar jogos, um quebra-cabeça, não vai ter fumaça, por que as fábricas não vão precisar fazer [...]".

Ficam expressas, tanto nos desenhos como nas falas, a preocupação das crianças com o planeta Terra. Na Figura 4, a criança explica: "aqui é o planeta, e as lixeiras, escrevi papel e plástico. Eu também plantei uma plantinha." Já na Figura 5, a criança coloca: "eu estou plantando uma planta e a abelha está fazendo mel. Escrevi aqui eu tenho muito amor pelas flores."

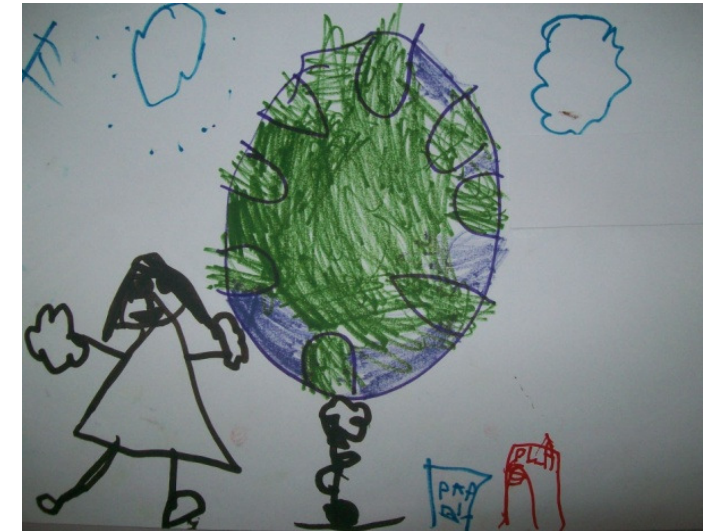

Fig.4: Desenho de G. P., cinco anos

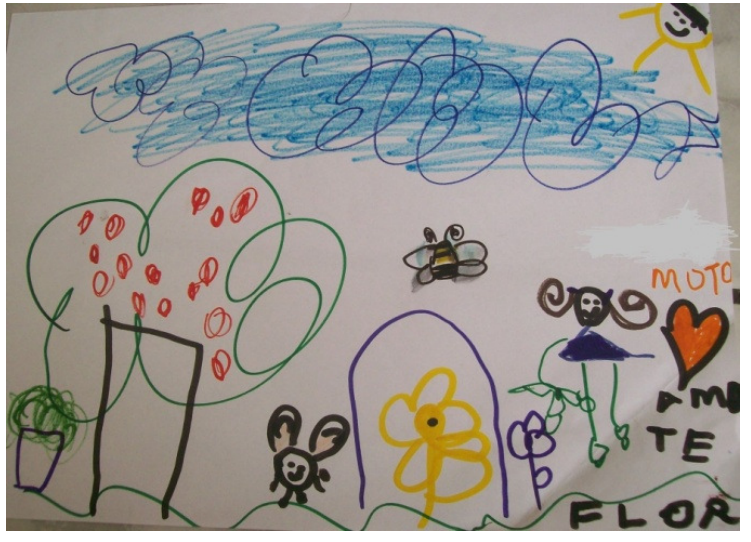

Fig.5: Desenho de M.G., seis anos

Nestes desenhos (Figuras 4 e 5), as crianças mostram mais alegria, comparada aos desenhos anteriores (Figuras 1 e 2), como um lugar bonito e gostoso de viver. Percebe-se que as crianças têm a compreensão de que fazem parte do meio ambiente, assim como que há uma interdependência entre os seres na natureza. Também, colocam sobre a necessidade do plantio de árvores, pois compreendem, mesmo expressando do seu modo, que estas possibilitam a retirada de dióxido de carbono da atmosfera, além de proporcionar sombra e contribuir para a biodiversidade.

Henn \& Bastos (2008, p. 335) defendem a discussão de ações que poderão ser feitas para ajudar a mudar as situações consideradas prejudiciais ao meio ambiente e, de acordo com os autores, se faz necessário evidenciar às crianças da educação infantil "os conflitos que existem por de trás das questões ambientais".

A partir disso, buscou-se demonstrar a viabilização de ações sugeridas, como atividades simples e possíveis. Nesse propósito, em princípio, foi proposto o plantio de mudas de árvores no 
pátio da escola, o que se deu através de trabalho e compromissos assumidos coletivamente (professoras e crianças). Pois, acredita-se que "o fazer/aprender não deve ser uma atividade externa ao aluno, mas conjunta, envolvendo o potencial intelectual do aluno e do professor aos meios de aquisição de novas informações passíveis de serem transformadas em conhecimento" (Araújo, 2004, p. 72).

Finalizando o trabalho, foi proposto um momento de criação com sucatas, atividade sugerida e motivada pelas crianças. Uma das crianças, que sugeriu e incentivou este momento, encontrou peças de isopor e logo pensou em criar um jogo de memória (número-quantidade. Ainda, com os retalhos de isopor, outra criança criou um robô. Uma terceira criança fez um colar com tampinha de lata de refrigerante. Assim, cada um construiu o seu jogo ou brinquedo com dedicação e muita criatividade.

É importante considerar esse aspecto, pois, segundo Fortuna (2008, p. 62), o ato de reciclar traduz uma postura, uma visão de mundo. Diz que o fato de algumas pessoas (crianças, pais, professores) acreditarem que "lidar com sucata é próprio de quem não tem dinheiro", ignoram que a perspectiva depreciativa de materiais naturais ou já utilizados expressa, na verdade, "dificuldade para criar, enternecer-se com a simplicidade, deixar-se desafiar e dar lugar a imaginação." De acordo com a referida autora

Essas considerações de Fortuna favorecem a compreensão de que as crianças participantes desta pesquisa constroem uma visão diferentemente de mundo e de viver neste mundo, e que a atividade de criação através de materiais recicláveis se constituiu em uma importante atividade educativa. Pois, como defende a autora, "inventar e recuperar brinquedos (e não só esses objetos, mas qualquer coisa) é uma manifestação criativa que revela uma atitude responsável em relação à vida e que se transmite na ação educativa como parte do processo educador" (Fortuna, 2008, p.62).

\section{CONCLUSÕES}

Através dos dados expostos e indiscutidos neste trabalho, verifica-se que todas as crianças adquiriram conhecimentos a partir das atividades desenvolvidas, demonstrando uma compreensão significativa em relação à temática abordada, as mudanças climáticas globais, entendendo que estas estão diretamente relacionadas com ao equilíbrio ambiental e a preservação dos ecossitemas.

Com esse estudo as crianças passam a compreenderam que as ações humanas, como o desmatamento, queimadas, o destino inadequado do lixo, a poluição gerada pelas indústrias e automóveis, desencadeiam consequências negativas ao Planeta Terra.

A partir disso, colocam-se como seres atuantes no sentido de cultivar e incentivar atitudes positivas com o meio ambiente, sentindo-se parte deste meio. E assim estimulam como consequência, a transformação de valores e atitudes de outros indivíduos, nos grupos sociais que fazem parte, sentindo-se parte integrante do meio ambiente e responsável pelo equilíbrio do todo.

Essas constatações mostram que as práticas em educação infantil podem criar campos favoráveis para a educação ambiental à medida que são levados em conta os interesses dos educandos para novas aprendizagens, como também são favorecidas as observações e interações com o ambiente social e natural. 
Por fim, cabe dizer que é uma satisfação compartilhar esta experiência de trabalho com crianças da Educação Infantil, no qual se busca, cotidianamente, transformar os interesses das crianças pelas descobertas de mundo, em campos favoráveis para a construção de uma nova geração comprometida e responsável pelo meio ambiente. Nesse sentido, as idéias que são apresentadas e discutidas neste trabalho servem para motivar a educação ambiental na educação infantil, mostrando que é possível e necessário.

\section{REFERÊNCIAS BIBLIOGRÁFICAS}

ARAUJO, M. I. DE O. A universidade e a formação de professores para a educação ambiental. In: Revista Brasileira de Educação Ambiental, n/ zero. Brasília: Rede Brasileira de Educação Ambiental, 2004.

BARBOSA, M. C. S.; HORN, M. da G. S. Projetos na educação infantil. Porto Alegre: Artmed, 2008.

BRASIL, Ministério da Educação - MEC/SEF. Referencial Curricular Nacional para a Educação Infantil: introdução, vol.1, Brasília, 1998.

BRASIL. Ministério da Educação. Parâmetros Nacionais de qualidade para a educação infantil vol.2, Brasília, $2006 . \quad$ Disponível em: <http://portal.mec.gov.br/index.php?option=com content\&view=article>. Acesso em: 24 jan. 2010.

BRASIL. Ministério da Educação. Parâmetros Nacionais de qualidade para a educação infantil vol.1, Brasília, $2006 . \quad$ Disponível em: <http://portal.mec.gov.br/index.php?option=com content\&view=article>. Acesso em 24 jan. 2010.

BRASIL. Ministério da Educação - MEC/SEF. Referencial Curricular Nacional para a Educação Infantil: Conhecimento de mundo, vol.3, Brasília, 1998.

FORTUNA, T. R. (Re) criar brinquedos, reciclar a vida. In: Revista Pátio, Ano xll, no 46 Mai/jul 2008.

FREIRE, Paulo. Pedagogia da autonomia. Rio de Janeiro: Paz e Terra, 2004.

HENN, R.\& BASTOS, F. P. de. Desafios Ambientais na Educação Infantil. In: Revista Eletrônica de Mestrado em Educação Ambiental, vol.20, jan/jun de 2008.

IPCC - Painel Intergovernamental sobre Mudança do Clima - IPCC, Mudança do Clima 2007: A Base das Ciências Físicas, Contribuição do Grupo de Trabalho I ao Quarto Relatório de Avaliação do IPCC, 2007.

MARTINS, G. A. Estudo de caso: uma estratégia de pesquisa. São Paulo: Atlas, 2006.

MINAYO, M. C. de S. Ciência, técnica e arte: o desafio da pesquisa social. In: MINAYO, M. C. de S. (org.). Pesquisa social: teoria, método e criatividade. 19 ed. Petrópolis, Rio de Janeiro: Vozes, 2001. 